\title{
Toward a Workshop in Theatre Phenomenology
}

Cover Page Footnote

This project was kindly funded by the Department of Humanities at Sheffield Hallam University. 


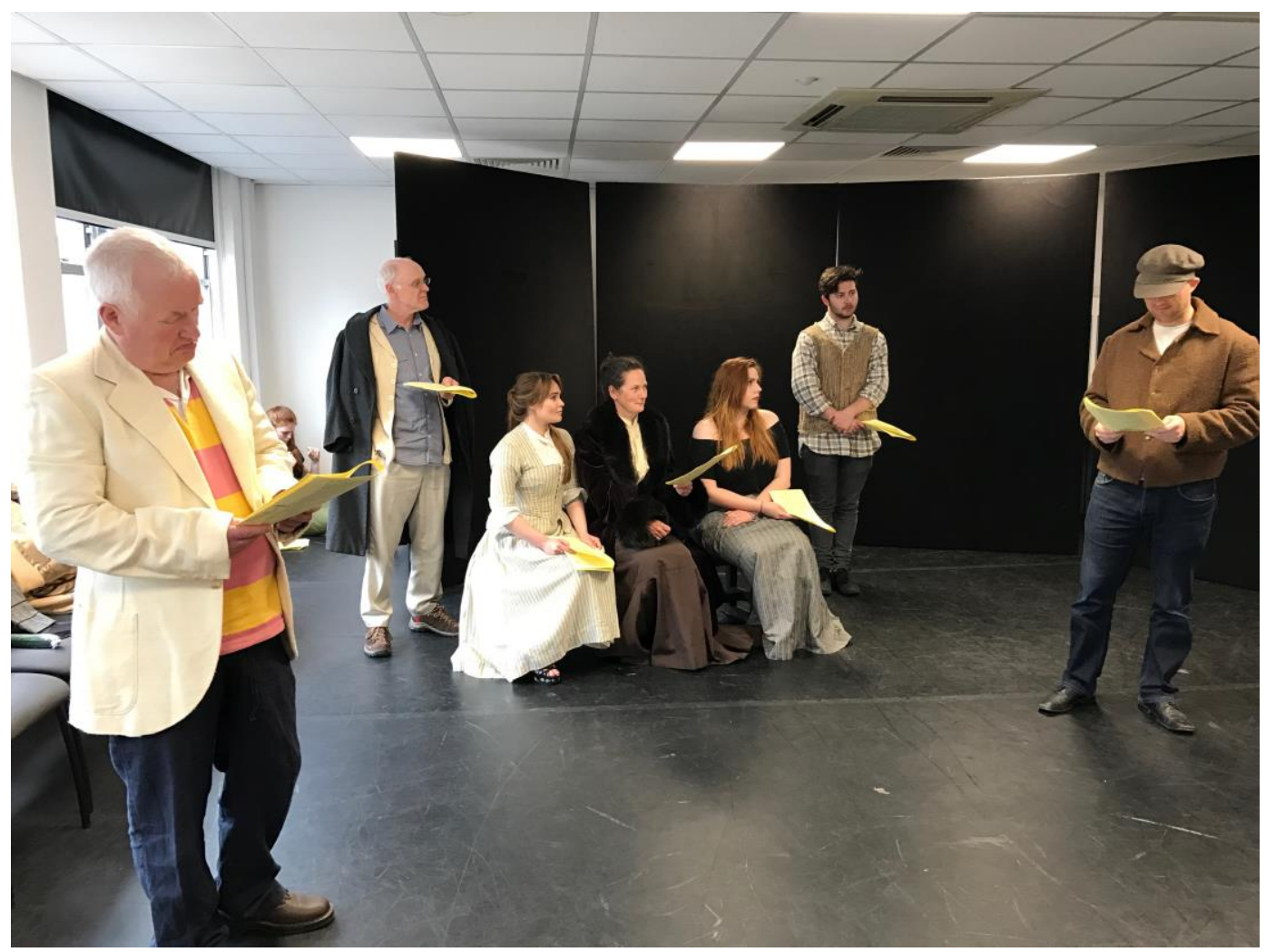

This written account with supplementary video footage outlines a theatre workshop at Sheffield Hallam University, UK in July 2017 aimed at investigating how philosophical phenomenology might be useful in the creative process. ${ }^{1}$ The workshop involved five professional actors from the Yorkshire region and four undergraduates working on Act II of Anton Chekhov's The Cherry Orchard, meeting over two days. Some of the later practical components of the rehearsal were led by Dr. Henry Bell, a theatre director of some years with a background in theatre - especially theatre in the round - and phenomenology. Although a similar approach might be adapted for many different types of performance processes such as devised and physical theatre, the focus here was on bringing a dramatic text to life. In many ways, the project formed the next step beyond my recently published introductory work Theatre and Phenomenology: Manual Philosophy. I have argued that actors can be understood as practical philosophers in so far as they investigate the relationship between self and world and develop an awareness of "being there" for the sake of performance. ${ }^{2}$ With this in mind, throughout the workshop, I presented brief introductions to some basic concepts of phenomenology including: involvement and worldhood; Being-with-others; Moods; and Temporality, explored in the exercises below. ${ }^{3}$ 
Each participant was given a digital voice recorder to reflect on a series of techniques and tasks aimed at focusing attention on their experience of objects, places, and rehearsal itself. In most of the video links below, footage of the exercises is complemented by audio reflections from selected participants.

\section{Theatre Phenomenology}

Phenomenology is the philosophical study phenomena-how the world shows itself to conscious experience. ${ }^{4}$ More commonly when invoked in the humanities and social sciences, the term is used to emphasize our embodied encounter with the world in contrast to a conception of mind separate from matter. It rejects a "correspondence theory of truth" in which propositions can be said to agree with a certain state of affairs in the world. Set against a philosophical tradition of "idealism" (all experience of the world is in our mind) and "objectivism" (the world exists independently of our perceiving it), phenomenology takes self and world to be so inextricably linked that it doesn't make sense to isolate one from the other. Take, for example, the activity of sailing a boat. The experience of the sailor is not just a complex set of calculations about wind speed, tension in the rigging and angle of the rudder. To know how to sail is more about "getting the feel" of sailing more than any set of propositions. The conscious awareness of the sailor is outside of their own body reacting to the conditions of the ocean and the movement of the boat. An extensive physical account of the processes involved does not even come close to the experience of sailing. Or to take a much simpler and famous example, to understand a hammer is not simply to be able to describe its material characteristics. Our understanding of a hammer is demonstrated when we grasp it and use it. Phenomenology, therefore, attempts to emphasize lived experience over philosophical abstraction.

Edmund Husserl, the founder of the phenomenological movement, attempted to describe consciousness and its contents by describing the essence of various modes of experience. Borrowing from psychologist Franz Brentano, Husserl developed the notion of "intentionality" - the idea that conscious mental acts always have content of some kind directed toward an object or state of affairs. In order to distill the essence of conscious experience, he proposed the "phenomenological reduction" or epoché-a process of suspending all judgments and assumptions about the world and the way that we engage 
with it. Moreover, he suggested that we step back from our everyday interaction with the world, which he called the "natural attitude," and focus on the mode of "givenness" of the experience, or the specific way in which an experience presents itself to physical and mental awareness. Later philosophers in the movement built on Husserl's ideas and focused on various aspects of lived existence. Common to most phenomenological approaches is a radical skepticism regarding traditional ways of understanding consciousness that reach for abstract explanation. Instead, the movement attempts to reconnect with "the things themselves"-life as it is directly experienced. Having said that, some forms of phenomenology study not only the experience of specific phenomena but also the conditions for the possibility of conscious experience in the first place. In this sense, phenomenology is a mode of enquiry that includes the enquirer and the enquiry as an object of investigation. Philosophy is never carried out by a detached and objective observer outside of history and culture, but only ever by a living individual involved in the world. In short, phenomenology is not the study of "mere appearances" but "the things as they are."

In contrast to many previous phenomenological studies of theatre that have drawn on phenomenologist Maurice Merleau-Ponty because of his emphasis on perception and embodiment, my work has largely drawn on Martin Heidegger's work, which centered primarily around "the question of Being." Rather than isolated subjects experiencing the external world, Heidegger's early work investigated the special type of "being there" that we have as humans. He appropriated the German word "Dasein" which can be translated literally as "being there," but can also mean "human being," "life," "to be present," "to be available," "to exist". In short, Dasein is the human subject-you, me and others with the same type of being that we have. In German, the word doesn't have a plural. Dasein is thrown into the world that has a pre-existing set of structures for the possibility of existence, both social and physical; it is temporal because it will one day come to an end in death; it cares about its own continuing existence; and ultimately it has the ability to enquire both into its own being and Being more generally. The fundamental basis of Dasein's experience is Being-in-the-world: we are always involved in activities, tasks, and projects that reveal the world around us in specific ways. In fact, Dasein is Being-in-the-world. Rather than step back from the natural attitude as Husserl had proposed, Heidegger tried to understand 
the human subject as it is "in" the world. More broadly, Heidegger suggested that we have forgotten how to ask the simple question of what "being" means, and part of his philosophical quest was to give an account of this forgetfulness.

The aim of our workshop was to employ some of Heidegger's ideas about Beingin-the-world in the creative process of theatre-making. If phenomenology provides a faithful account of the way that we experience the world, then it should also be helpful in creating a role because it can direct us towards aspects of our "being there" in the creative moment and provide a framework for approaching the conscious experience of a character within their world. In other words, if we can apprehend the necessary conditions for the possibility of "Being-in-the-world," then those conditions may be useful in constructing a fictional world on stage, as well as developing an awareness of the "being" of artists involved in the creative process.

The workshop had three phases: developing an awareness of one's own experience of the world; applying observed elements of worldhood to a character; and reflecting on the creative process of the actor as they developed their part. Given the limited time frame of the rehearsal, the workshop was merely a preliminary examination of how phenomenology might inform and contribute to the artistic process of theatre-making. Rather than establish an entirely new and unique approach to rehearsal, however, theatre phenomenology as employed here sought to develop the performers' awareness of their engagement with the world and their experience of the rehearsal process. We used phenomenological concepts to re-articulate, enhance, and stimulate the current theatremaking practices of this group. As opposed to meditation practices aimed at achieving calmness and being present to immediate experience, these phenomenological exercises were aimed at approaching everyday engaged activity in the world. In one sense, the rehearsal was unremarkable in that it simply involved a read-through and some preparatory scene work. Nevertheless, the key innovation rested in a focus on a new vocabulary for talking about self, place, time, and being. Without the pressure of a finished product at the end, the emphasis was on process - including method and exploration. The task was not to discover a radically new way of preparing for performance, but to provide a fresh way of seeing what we do in both in everyday life and on stage-or, in other words, what constitutes a world in the first place. 
Chekhov's The Cherry Orchard was chosen as the text for investigation because it deals with a range of phenomenological themes even though there is no evidence that Chekhov was drawing explicitly from, or even aware of, the philosophical movement. ${ }^{6}$ These themes include Being-with others, being alongside things, Moods, Anxiety, Beingtowards Death, Authenticity, and Historicality, some of which are explored below. Indeed, Chekhov's theatre was considered to be a "theatre of atmosphere" (nastroyenie) by Konstantin Stanislavski and Vsevolod Meyerhold insofar as it investigates a palpable intersubjective mood at a historical shift in social and technological organization within society. ${ }^{7}$ Atmosphere is not merely the meteorological environment in this sense, but the "being there" of this group of characters who are out of touch with one another and with the prevailing world beyond the estate. Arguably, each of the characters in the piece demonstrates a spectacular failure of Authenticity - in Heidegger's terminology — in that they neglect to communicate with each other and fall short of connecting with the reality of their existence in the world of this nineteenth-century Russian country estate. They also flee from decisions about their own lives by seeking distractions and amusements to avoid the impending sale of the family property. Act II contains an iconic moment in modern theatre history: the mysterious sound of a breaking string heard off-stage, a sound that serves as a counterpoint to the theatrical realism of the play itself. Caught up in personal preoccupations, this group of impotent aristocrats and their servants largely fail to observe the world falling apart around them. From such a case study in dysfunction, we can begin to put together what constitutes a world — a quintessentially phenomenological task.

\section{Encountering Being: Observing Oneself}

\section{Phenomenological Walk-Observing in Movement}

After an introduction to the workshop outlining the broad purpose of the project, our first practical task was merely to take a walk outside in the surrounding vicinity of the rehearsal studio. As it happened, we were situated next to the Sheffield bus interchange in the east of the city. The participants were instructed, on a five-minute round-trip, to walk in silence and observe their lived experience of the world. These observations could include thoughts and perceptions, specific bodily sensations, sounds and smells, and broader 
orientations within the environment. Some of the participants found the task difficult, in that their own thoughts intruded on the activity. But in a sense, that too was part of the exercise: we always bring a set of dispositions to our experiencing that inflects the way that the world is revealed. Heidegger calls these Moods: "dispositions" that we always hold in relation to the world - how we find ourselves in any given situation. The exercise also revealed the myriad of experiences that pass by even in a short durational period and in a simple task. These included quite literally a reaction to atmosphere in the rain, an awareness of self in the environment, a relationship to others in that space, an estrangement from the conversations and activities of others, and even bodily sensations such as being hungry:

https://youtu.be/a4pKm81lLyE

Most of the time, of course, we don't simply walk for the sake of observing our own experiences; we walk for a reason. For example, I catch a bus so that I can go and visit my mother; or I try to arrive on time to the tutorial that I have missed for the last two weeks; or I fetch some unusual ingredients from the natural food store so that I can make an allergen-free cake for the class. Without a separate purpose, this type of phenomenological walk can make participants feel a bit "naked." Nevertheless, solely observing for its own sake can prepare actors for observing engaged activity too. Method Acting, for instance, holds that actors can use their individual past experiences as a rich resource for performance through the process of sense memory and emotional recall. Putatively, the more that you practice, the better you will be at recording and recalling experiences that can help to build a part. Secondly, it is also worth noting that even though there was no external goal to this walk, it was not simply detached from the world. The task itself was the purpose: to observe experience for the sake of the workshop. And as suggested in the introduction above, humans are always involved in activities and tasks as necessary conditions for existence.

\section{Observing in Stillness}

This phenomenological walk was supplemented by a second task in which the actors found a space in the studio and let the environment reveal itself to their 
consciousness. This time, the internal awareness of participants came to their attention. In many respects, these tasks were similar to mindfulness exercises from applied psychology and even Stanislavski's concentration of attention tasks. The participants were asked to concentrate their awareness on their immediate environment. If their minds drifted off and thoughts came in, the actors were asked to accept those wanderings and re-adjust their focus and attention once again on the room they were in. The actors stood in the rehearsal space together, so they were also aware of each other in the room. Bert States notes that simply placing a piece of furniture on a stage heightens audience awareness of elements of its very being. ${ }^{8}$ How much more so is this the case with a person in a scene? The frame of the exercise turned the actors into phenomenological objects of attention-both for themselves and others - as well as observers. They were both inside and outside of themselves as subject and object of the task - or rather they switched between these modes of awareness. The participants noted the sense of being watched because as they became aware of those standing in the space around them, they also realized that they were objects of awareness to the other actors carrying out the same task. This recognition, in turn, led to an attentiveness of self and their own being in the space. The self became "other." This double awareness is, of course, related to Denis Diderot's "paradox of the actor" as both participant in the scene and cool observer and controller of their actions. Part of the actor's task is to achieve "naturalness" in the performing space and transcend self-consciousness without sacrificing self-control. Stanislavski calls this "solitude in public."

\section{https://youtu.be/spMbdmffkfU}

\section{Describing an Object}

The third task was to attend to an object of each participant's choosing and then describe it to a partner. Again, I suggested that participants concentrate on the perceived qualities of the object - its shape, color, size, texture etc. But I added a twist by requesting that the speaker describe the object as if they were trying to communicate with an alien. In this way, participants could presume no prior knowledge of the object itself and its use or context in the human life-world. Despite the impossibility of the task (presumably, aliens would not have a working knowledge of our language either) the challenge was to unpick the presumptions about equipment and objects in our environment and the way that we 
engage with them. This time, each of the participants described the object to another person in the group. By listening to other descriptions, the actors also perceived different perspectives and ways of describing that they would not have noticed themselves. In this way, not only did the being of the object come to the fore, but also the language and its limitations through which we describe the world. This, in turn, raises the question of how our language also sets up a set of conditions through which we experience even the simplest object in our environment. And it also asks whether language is always the primarily the determinant of the way that we experience the world in the first place.

This task began to touch upon the phenomenon of worldhood-the complex set of involvements, activities, and entities that humans encounter in their environment. In Heidegger's phenomenological terms, we never primarily engage with objects in their sheer materiality, but rather in terms of the "use" to which we might put them-i.e., as "equipment." As mentioned in the introduction above, we encounter the being of a hammer not when we just stare at it, but when we grasp it and hammer with it.

\section{Describing an Action}

The fourth task following from this idea was to describe an everyday action such as tying a shoelace-again without making any assumptions of knowledge in the interlocutor. The challenge was to unpick the interconnected meaning of actions and objects that surround the immediate description. So, if you were to explain the idea of tying a shoelace, for example, then you would need to describe a shoe, its parts, what laces are and how they hold together, what the action involves physically, what it is "for," etc. Ultimately, this stringy length of material holds footwear together for the sake of the wearer's comfort so that she or he can carry out other tasks. Shoes allow us to go about our daily business of living. Indeed, there is a whole world that can be imagined in the work of the shoemaker with the myriad of tools and tasks required to put the shoe together and perhaps even the multi-billion-dollar global commercial industry of selling sports shoes. The meaning of a shoelace is determined by the world of the wearer. Of course, this level of social complexity is impossible to communicate without presumed knowledge, but it also shows how acculturated even the simplest of motor activities and physical tasks that we undertake are. Each choice or assumption that the actor makes about this world of 
involvements affects the way they carry out each action together with its meaning and significance. By making the network of involvements explicit, the actor is presented with innumerable choices of action and behavior to flesh out the world on stage.

\section{https://youtu.be/Lo5fgh9TWQ4}

A second part of the task involved sharing these descriptions with another participant; we asked cast members to reprise their description, this time while a partner "embodied" the action in some way. By physicalizing the communication, there was an added dimension to the task. The idea that knowledge is "in our fingertips" was shown by the demonstration. At the same time, the action also became strange by the mere fact of its being represented. In phenomenological terms, this idea is called "pre-predicative" or "prereflective" knowledge of the world. We exhibit our understanding of our environment by our activities and this is not necessarily in a verbal or intellectual manner. Cast members variously chose to describe and show placing on a pair of glasses, fastening a wristwatch, and even putting on a bra. What became apparent was that these largely unconscious behaviors also bear socio-political significance once they have been made explicit. One participant noted how putting on a bra, for instance, pointed towards conforming to various gender norms in social interaction and dress conventions in addition to any practical value. Another actor observed how putting on a watch indicated a certain set of constraints around social behavior including being on time, politeness, and perhaps even ostentation-if the watch happens to be of an exclusive brand, for instance.

\section{Describing a Nearby Place}

The next activity was to find a space in our rehearsal studio or adjoining rooms and report its qualities and characteristics. It was notable that the participants began to express evaluations of architecture and interior décor in these descriptions. Even though the task was simply to describe what they saw, it was inseparable from what how they felt about their surroundings. For instance, the brutalist architecture felt oppressive for one participant; the bland office-like furniture together with the generic color scheme invited a sense of anonymity for another. For some of the actors, these locations were familiar as types of spaces: classrooms, rehearsal rooms, and corridors. Each place evoked a feeling 
of comfort or familiarity or anxiety and being out-of-place. So over and above the physical dimensions and characteristics of the sites described by the participants, the resulting descriptions immediately tapped into the idea of personal connection to the environmenthow it made them feel. This individual relationship to place forms a crucial frame for Being-in-the-world capable of affecting our mood, interaction with objects, and Beingwith others there in the world.

\section{https://soundcloud.com/daniel-johnston-411177423/desciption-of-place}

\section{Describing the Experience of Not-Being-at-Home}

In a follow-up exercise, we formed a circle of chairs - not unlike a group-therapy session - and I asked the actors to close their eyes and imagine a place that they felt like they were not at home. Rather than use our audio recorders at this point, we talked to the rest of the group without recording. This provided a slightly different dynamic to the narration because of the possibility of open conversation, responses to description, and follow-up questions to probe the individual's experience. One cast member talked about visiting an elderly relative in a nursing home. She described how such a place is both a public and private space at once, complete with familiar furniture and décor, but surrounded by other residents of the home. Occupants of the dwelling never entirely have the space entirely to themselves. In such a place, you can make a cup of tea and sit in a comfortable chair, but for some residents being able to move around the space is not a possibility because of their condition; and the shift-staff coming in and out of the area remind us that this is a workplace too. The participant also noticed that she had become sensitized to the existence of nursing homes everywhere from that point - she began seeing them wherever she went. The invisibility of nursing homes depends on one's own worldthey don't matter to you until you need to visit one. Another cast member observed that places change in their familiarity or feeling-at-home-ness. A family home, once sold, loses something and becomes a series of rooms, or perhaps comes to stand in for "what once was" rather than what is now. There is a distinct temporality in the way that we related to place. And in many respects, of course, this is the story of The Cherry Orchard as the estate makes a transition from this family's home to someone else's place. 


\section{Describing a Person: Who Are You When You Are With Them?}

In the final task of the "Observing Oneself" section of the workshop, I asked the actors to describe a person with whom they were familiar. The emphasis here was on thinking about who you are when you are with that other person. Participants discussed the topic in pairs, and it was immediately clear that the actors had much more to say on this subject than the previous exercises. Many of the cast chose to describe people they were very close to-where they met, what they loved in the other person, particular moments that summed up their relationship. Part of the pleasure and interest came from the emotional connection to their chosen person. For one participant, the description was much more about what to disclose to an audience because it was a matter of selecting what to say or not say in this social situation. And yet there was something odd about the description because it wasn't so much a conversation, in the sense of a dialogue, as a one-way communication. The artificiality of the description exercise itself highlights a phenomenological point about our "being there" with one another in the world. It is a matter of sharing and reacting, blocking or questioning, asking and dismissing in conversation. In our response to others, we demonstrate care or concern about what is being said and its meaning to the interlocutor. In phenomenological terms, this is an example of an "authentic" mode of Being-with-others. Authenticity in this sense means genuine concern for others as human beings there with us in our environment rather than treating them as mere objects to be used. It also demonstrates that others there in the world are an essential and necessary part of who we are ourselves. On the other hand, the exercise also showed how similar all of our human relationships are on one level. For instance, two participants talked about close friends and it was remarkable to them how the same sorts of things came up in both descriptions.

\section{Imagining a World: Work on a Role}

\section{A First Reading}

After these initial exercises and reflections in the morning, we settled down in the afternoon for the first read of Act II of The Cherry Orchard. The text we worked with is available $\langle$ HERE $>$. Some cast members were more familiar with the dramatic text than 
others and brought different perspectives on various aspects of the play, including historical Russia, theatrical conventions of the time, and working with a play script as text in performance. I gave a summary of the dramatis personae in order to aid in understanding and an overview of some of the significant action from Act I. Madame Ranevskaya's family and her entourage return to the country estate from France. As the two days of rehearsal developed, the idea of place-including where the scene is set, the parts of the fictional space, its nearby locations, and other far-off places of significance including Moscow and Paris - became crucial to the process. In this sense, the preliminary exercises above shaped this first encounter with the text. For example, the actors continued to search for their character's relationship to their surroundings, movement within the space, internal association to place, concentration of attention, relationship to objects, involvement in tasks and activities, whether they felt "at home" or not, and the persisting presence and significance of others there- or not there - in the world. Of course, I would suggest that a different dramatic text would benefit from a different set of exercises sensitive to the needs of each text, its world, and theatrical conventions.

The main point of this first reading was to find a point of departure in activating some of the exercises and phenomena approached above. Focusing on Chekhov's play opened-up a concrete discussion of some of these key phenomenological ideas and possibly even subjected them to critique. In an ideal workshop, of course, the participants would have had more of an opportunity beforehand to research their backstory and given circumstances in order to approach the text as faithfully as possible. Such research also highlights the collective and collaborative work of the director and/or dramaturge and other members of the creative team in tracing accurate historical information that might feed into the world of the play. The rehearsal necessarily involved practice as research in the sense that each reading and run-through raised the need for deeper research into elements of the world being portrayed and shared reflection upon how they can be brought to life through the lived experiences of the actors.

The initial reaction of cast members was to note how each of the characters interrupts or ignores each other when they take turns to speak without logical connection to the preceding dialogue. Over and above the tendency of individuals not to listen to each other, the actors also observed a generational split with the older and younger characters, 
a class separation between the aristocrats, servants and the rising merchant class. Chekhov cleverly inverts the presumed status of particular characters-perhaps most notably towards the end of Act II, in the power of the tramp over the family. Perhaps this signifies a failure in this group of people to connect meaningfully with the outside world. And still, sometimes the characters pick up on thoughts, connections, and dialogue later in the scene as recurring themes and variations in musical form. Yet again, the failure of each of these characters to "be there" with one another was clear. The central romantic relationship between Trofimov and Anya, for instance, is undercut in a tension between his intellectual and philosophical zeal, the emotional connection between the two, and the disruptive force the rest of the family heard at the end of the act in Varya's call from off stage. As a result, the text opens itself up for an investigation of Being-in-the-world because of the very many failures and deficiencies in each character's Being-with one another-in terms of relationship to place, distraction by objects in their environment, lack of concentration of attention, lack of mutual tasks and activities bringing them together, their feeling "not at home" on this estate, and frequent fleeing to be somewhere else rather than their present situation - if only in focus of awareness. There was an apparent correlation between the dramatic form of the play, Chekhov's arrangement of action, and approach to rehearsal we were attempting to make through phenomenology.

\section{Who Am I and How Did I Get Here?}

On the second day, the actors had time to reflect on their initial reactions and start to develop a sense of "who" their character might be. The question of "who" is central to Heidegger's conception of Dasein. We are never merely things like rocks, stones, and trees; we have an existential capacity to look into our own being and an intertwined connection with others there with us in the world. Thus, the session began with some character discussion —what Stanislavski would call "round the table analysis." A substantial amount of the conversation after the second read-through centered on Chekhov's description of the mise en scène at the beginning of Act II. A keen sense of space and its significance permeates the scene - the crooked shrine and ancient bench harking back to the history of the estate, the telegraph poles and city in the distance indicating the encroaching modern industrial world, the poplars on one side providing a screen from public scrutiny, and of 
course, the cherry orchard itself (possibly an historical anachronism, as this area of Russia may not have had any at the time) signifying a natural beauty in contrast to the worth of the real-estate as a potential site for holiday lettings.

But keen to get back onto the floor, we soon moved on to some more practical exercises as we began to look through the props and costumes provided for the workshop. Dressing up proved to be an important part of character development as the materials and forms of the garments helped to shape the way that the actors inhabited the stage. In contrast to productions where costumes are often the last element to be introduced to rehearsal, their physical characteristics and phenomenological significance could be investigated much earlier in the process here. The costumes themselves came from the Sheffield Theatres stores and brought with them a sense of historical significance: Madame Ranevskaya's dress had been worn by the famous English actress Joanna Lumley ten years before, for instance. And there was something very satisfying about seeing each of the actors in costume: it summoned up a sense of vivid reality, for instance, as the garment restricts the actor's breath, or enabled only a limited range of movements.

\section{Describing Fictional Place: A Walk to the Estate}

Beginning with moving around the space, the actors were led through some kinetic activities at various speeds. We investigated the character's walk-counting down from ten to one and then stepping into character as if catching up like a ghost from behind and then inhabiting that person. One participant particularly liked this image as it encapsulated the idea of approaching the role in an embodied way.

From this point, we transitioned into an activity imagining each character walking from the nearby train station up to the Ranevsky estate. This activity included thinking about what type of path or route they had taken to the setting and the surrounding scenery. What was interesting about the resulting discussion was that each of the actors had slightly different interpretations of place, including the width of the path, the ground underfoot, the position of various landmarks, and so on. These differing interpretations raised the intriguing question about representing a world on stage and possible discrepancies of vision among the cast. Sometimes divergences may be useful, of course. Without a director making definitive choices here, there was variation — which may be possibly cleared up 
with further work investigating the text. Some of the more experienced cast members were less at ease with this "openness" to choices because, in many professional processes, such details would be decided by the director and creative team beforehand.

\section{Describing an Object Meaningful to the Character}

As a twin exercise from the first set of tasks above, this time the actors described an object of significance to their character. Standing in front of the rest of the group, they were able to explain their feelings about various objects and why they were of personal importance. The objects themselves disclosed the world of concern for the character, as set up by the exercise on involvements in the Describing an Action section above. Lubov (Madame Ranevskaya) chose her expensive purse that reminded her of Paris and which was luxurious in its design, expense, and detail. Yasha chose his cigar that also reminded him of his days in France and the new world of liberation he experienced there. Lopakhin chose his watch that was a symbol of his new found status as a gentleman and self-made individual in his world of trade. Obviously, props and costumes form an important part of the sign system of the stage, but here, the actors were able to explore their character's personal investment in their world together with the broader symbolic meaning of various objects in the action.

\section{Describing a Significant Person from the World of the Play}

Again, in an exercise correlating to the first day, the actors in character were asked to describe someone they cared for within the world of the play. But this time, if the chosen character being described was part of the cast, then the relevant actor would stand up in the space and the participant performed a commentary on that person. This was a particularly good way of exploring backstory in practice — a technique similar to "hot-seating," where actors are asked a series of questions while remaining in character. The resulting exercise produced a series of "secret missives" (declaring love), confessions (owning up to guilt) from one character to another, or "therapy revelations" (explorations of mental processes in accounting for a decision). Each of these articulated the "inner working processes" of what the character felt from a psychological point of view-but perhaps never had explicitly said - and maybe even why that was the case. It is, of course, possible that the 
character within the play never has complete access to their unconscious motives that might be implicit in these articulations.

\section{https://youtu.be/Ka1xbjiR3Aw}

Regarding phenomenology, this description of another person reveals the idea that we are never simply isolated subjects in the world. We always exist in the "with-world" of those we care about and those who dwell alongside us in the world. In this sense, we are never truly alone because the being of others follows us through our own encounter with the world. What's more, others in the world can be experienced even in inanimate objects. This is part of the meaning of Trofimov's speech about the cherry orchard containing the souls of all of those serfs who worked the land in previous generations and the ethical responsibility of the current generation to honor and value them as human beings:

All Russia is our orchard. The land is great and beautiful, there are many marvelous places in it. [Pause] Think, Anya, your grandfather, your greatgrandfather, and all your ancestors were serf-owners, they owned living souls; and now, doesn't something human look at you from every cherry in the orchard, every leaf and every stalk? Don't you hear voices . . .? Oh, it's awful, your orchard is terrible; and when in the evening or at night you walk through the orchard, then the old bark on the trees sheds a dim light and the old cherry-trees seem to be dreaming of all that was a hundred, two hundred years ago, and are oppressed by their heavy visions. ${ }^{9}$

Yet again, there is a disjunction between these noble thoughts expressed here and Trofimov's actions that are equally neglectful of those around him because of his blinkered focus on political ideology.

\section{Imagining the Place Your Character Really Is}

Dr. Henry Bell introduced one of the most interesting rehearsal techniques explored in the workshop. The actors read through a section of the text, but at each moment where the character's conscious mind was somewhere else other than where they were in the scene, the rest of the cast would jump in and create that setting-not unlike the improvisation game of "space jump", where actors freeze at various points in an improvisation and must continue from that position in a new fictional setting. For instance, Lopakhin was off at the auction for the estate in his mind when talking to the Ranevskys; 
and Gaev was back at the restaurant or playing billiards at the club in town. The exercise helped to physicalize the internal mental processes of these characters particularly with respect to place. Stanislavski would characterize this in terms of a discrepancy between internal and external action.

\section{Listening and Not Listening}

In a later section of rehearsal, Dr. Bell asked the actors to read through a portion of the text but take note of whether their character was listening to their interlocutor at any given moment. If they were not engaged and hearing what the other person was saying, then they were instructed to walk away. The result was an interesting visualization of the connection patterns of awareness and attention in the scene. Each of the characters turned and walked off when they were being addressed except for Yasha who seemed to be taking in the whole scene. The exercise gave a concrete physicalization of the connections - or lack thereof-between characters. In a sense, it was also an exploration of the relationship between text and subtext - the meaning of the words is something other than what they literally denote. On the surface of it, the characters seem to be talking to one another, but on deeper consideration, they are very much caught up in their own world rather than connecting with one another in any meaningful sense. In phenomenological terms, each character is inauthentic in so far as they fail to acknowledge one another as beings with the same type of being as their own. They flee from the urgency of action in their immediate situation - not in the least the sale of the estate - and also neglect to acknowledge the relationship between their loved ones and their own being. Yasha, on the other hand, seems to be using his knowledge and observation of this group to further his climb up the ladder of social status. Inauthenticity, in this case, is "being somewhere else"-not "being there."

\section{Reflecting on Oneself in Performance}

\section{Top and Tail of the Act}

The final section of workshop activities on the afternoon of the second day involved a run-through of the beginning and the end of Act II in a moved reading, with script in hand. There was no premeditated blocking of the scene and the actors were given free rein to move on impulse and react to the moment as appropriate. In fact, we had a false start to 
the scene as the director encouraged the cast to connect with "the world of the play" as we had been working toward. We hadn't done much work on this opening section, and indeed some of the actors took on a doubled role that they hadn't played to this point. For instance, Charlotta the governess was doubled here by the actor who had been playing Lubov. In a way, this was a serendipitous choice, as Charlotta herself does not really know much about her family history and heritage, and almost seems to have stumbled into this world without her own past. She is astounded and puzzled by her surroundings and her existence. She also carries a rifle, perhaps reminiscent of her childhood in the fairground. And strangely, a second gun appears on stage with Epikhodov who doesn't seem to know which direction he should go towards in the future - to shoot himself or let himself go. Each gun carries an existential significance pointing towards the past from which each character has arrived and the potential end that imminently awaits them as human beings. But each gun fails to fulfill any practical function and serves instead as a symbol of dysfunction in this world The phenomenological examination of "who" for both Charlotta and Epikhodov that we were attempting in the exercises to this point was constituted by a lack-in this case of self-knowledge and resolute action of each individual in their circumstances. The actor's struggle with this question of "who?" found a fictional counterpart in these two characters.

It was noteworthy on a more concrete level, however, that some of the staging from the previous versions remained with the actors. In particular, the stage set-up remained inthe-round with audience members on all sides, although the black theatrical flats still preserved some of the directionality of the scene. At the very least, a residual spatial awareness of different elements of the fictional world was mapped onto the participants' performances. Indeed, the very last moment of the act where Tromifov and Anya exit was punctuated by laughter as they worked out which way it was down to the river away from Varya's offstage call. The following recording shows the final few minutes of the piece as an example of the work:

\section{https://youtu.be/a2QzUvFhHJk}

\section{Approaching Phenomenological Reflection}

The actors were then given the opportunity to reflect on their conscious awareness in the scene and observe one another in performance through their voice recorders after 
this run. It was intended that the performers might reflect on their focus and attention in the scene and reconnect, evaluate, and adjust their character and actions within the performance. In many ways, the process links in with Stanislavski’s “Active Analysis", by which actors work through a series of improvisations and return to the text each time to approach the scene asymptotically.

However, what actually occurred in these reflections- for the most part-was a commentary on the scene's connection with the immediately preceding exercises. The actor playing Charlotta, for instance, reflected on where her character "really" was, and her sense of ease in this area of the family estate. She also noted the strange relation to the audience in articulating her thoughts on stage - not as a soliloquy because of the conventions of naturalism at play — but as a kind of philosophical musing in itself. And this effect added to the way in which the other characters in the scene weren't listening to her anyway — a fact that she acknowledges and accepts explicitly:

\section{https://youtu.be/tU1UVMZGKgY}

Ideally, therefore, there would be much more time and scaffolding for the reflective process here. It was useful to have the audio recorders as a personal way into the actors' experiences although there is always the possibility of self-censoring and "performing" one's own acting process rather than reflecting with as much honesty as possible. Nevertheless, the results were intimate, not stilted, and perhaps - most importantly - not academic and cerebral. The aim of a phenomenological reflection was not to describe aesthetic judgments about the process or whether the performers liked that section of the workshop or not. It might even be useful to have a set of prompt questions about objects, place, others there in the "with" world, Temporality, Moods, Authenticity, and Historicality. Nevertheless, each of these elements of reflection should emerge from the experience of performing the scene and "return to the things themselves." In this sense, the process itself can enter into dialogue with philosophy and present contradictory, conflicting, and alternative accounts of the way we experience the world. 


\section{Conclusion}

In a final debriefing at the end of the process, the participants reported that the vocabulary derived from the discussion in philosophical phenomenology gave them a new way of understanding their own practice and developing an approach to a role. The emphasis on practical exploration apparently allowed the ensemble to progress much more rapidly than other creative processes that many of the cast members had previously experienced in rehearsal. The concept of "world" seemed to come up more frequently in discussion as the workshop evolved and some of the actors even began to use "authentic" and "inauthentic" to describe an attentive way of Being-with one another or what was lacking in their character.

Although many of the exercises that we experimented with could easily be recognized from existing techniques, each task was framed differently here through a phenomenological perspective. So for instance, each description and task focused on phenomenological frames such as: the deep connection between Dasein and world; an awareness of Mood and existential disposition in self and character; the relationship between world, tasks, objects, time and place; and the intertwined relationship between self and others there in the world. Rather than investigate individual psychology and physical processes, phenomenology sees the "inside" and "outside" of our conscious experience of the world as a derivative mode of understanding self: most of the time we just go about our everyday business and activity. And rather than see individuals as isolated subjects, phenomenology also emphasizes the interconnected and co-constitutive relationship between self and other. What makes us special in the world is that we have the ability to inquire into our own being, although in The Cherry Orchard, the characters fail to do so. We "light up" the world through our interaction with it. In Chekhov's play, a sense of place very much came to the fore as we thought about what it means "to be at home."

Over and above the investigation of character, the object of research here was also each performer's own self and their experience of performing. Of course, there is always a danger in qualitative research involving the discrepancy between participants' reported awareness and their actual experience, as well as self-censoring, unreliable recollecting, and so on. But the process of rehearsal is an inter-subjective co-authoring of a creative work that develops a sense of openness and attention to self and other. This rehearsal was 
dialogical in that the participants explicitly shared their experiences and reflected on their practice. And it is entirely possible that such creative practice can offer a genuine contribution to philosophy itself because of its emphasis on embodied activity over and above language and verbal description.

This project was quintessentially practice as research in that there was always an element of gathering sensory data, creative resources, and background information that might aid in imaginative engagement. But this was also coupled with critical reflection on the practice itself. Sometimes this was found simply in attending to one's own experience of the world. The "round the table" analysis section of the project was a form of group research and interpretation that fed back into the work. Nevertheless, this workshop demonstrated the rich potential of putting philosophical ideas into practice too. I have argued elsewhere that creative works can also participate in philosophical dialogue and present a specific "phenomenology" that might be at odds with other articulations - acting as "manual philosophy." I have previously attempted to interpret existing artistic processes as phenomenological in nature in their own way. For instance, Stanislavski's approach to acting can be seen as a phenomenological investigation of worldhood and action, Brecht's theatrical interrogation of social relationships as a phenomenology of political action, and Artaud's Theatre of Cruelty as a phenomenology of spiritual and material resistance to literary and linguistic expression. Here, the actors in this workshop began to explore the notion of what a world is through Chekhov's text and situate different worlds as they intersect and touch upon one another through their characters. The danger is to superimpose a pre-given understanding, interpretation, and meaning to a dramatic text. Theatre phenomenology — of the type approached here - allows the "being of the work" to arise from "the things themselves" including the being of the actors, the dramatic text, and attuned self-reflection on the part of participants in the creative process.

\footnotetext{
${ }^{1}$ Written permission from actors and creative artists involved has been obtained.

${ }^{2}$ Daniel Johnston, Theatre and Phenomenology: Manual Philosophy. (London: Palgrave, 2017); "Stanislavskian Acting as Phenomenology in Practice", Journal of Dramatic Theory and Criticism, 26, no.1 (2011): 65-84.

${ }^{3}$ I capitalize Heideggerian terminology in translation here to indicate each word's specialized employment in this context. For the main concepts in this essay, I draw upon Martin Heidegger, Being and Time, John Macquarrie and Edward Robinson (trans.)(London: Blackwell, 1962).
} 
${ }^{4}$ For an introduction and overview of phenomenology, see Dermott Moran, Introduction to Phenomenology (London and New York: Routledge, 2000).

5 Phillip Zarrilli, "An Enactive Approach to Understanding Acting”, Theatre Journal 59, no.4 (2007): 635-647; Stanton Garner, Bodied Spaces: Phenomenology and Performance in Contemporary Drama (Ithaca, NY: Cornell University Press, 1997); Alice Rayner, To Act, To Do, To Perform: Drama and the Phenomenology of Action (Ann Arbor, MI: University of Michigan Press, 1994).

${ }^{6}$ Mark Fortier, Theory/Theatre: An Introduction (New York: Routledge), 48-54; Rose Whyman, Anton Chekhov (New York: Routledge, 2011)

${ }^{7}$ Vsevolod Meyerhold, Meyerhold on Theatre. Edward Braun (trans. and ed.) (London and New York: Bloomsbury, 2014), 23-33; David Allen, Performing Chekhov (London and New York: Routledge, 2000), 13.

${ }^{8}$ Bert States, Great Reckonings in Little Rooms: On the Phenomenology of Theater (Berkeley: University of California Press, 1985).

${ }^{9}$ Anton Chekhov, The Cherry Orchard, trans. Julius West, last updated 27 March, 2016, https://ebooks.adelaide.edu.au/c/chekhov/anton/cherry_orchard/act2.html 